\title{
Utvikling av begrepstester for å evaluere læringsdesign
}

\author{
Anita Nordeng Jakobsen ${ }^{1}$, Per-Odd Eggen ${ }^{2}$, Rolf Jonas Persson ${ }^{2}$, Lisbeth Mehli ${ }^{1}$ \\ ${ }^{1}$ Institutt for bioteknologi og matvitenskap, NTNU - Norges teknisk-naturvitenskapelige universitet \\ ${ }^{2}$ Institutt for fysikk, NTNU - Norges teknisk-naturvitenskapelige universitet
}

\begin{abstract}
Motivasjonen for å endre undervisningsopplegg er å øke studentenes læring. For å måle effekten av endringer eller identifisere vanlige misforståelser innen fagområdet matmikrobiologi har vi utviklet en begrepstest (Food Microbiology Concept Inventory). Testen ble videreutviklet fra lignende tester i mikrobiologi og forfatternes egne erfaringer. I tillegg ble matbransjen spurt om hvilken mikrobiologikunnskap som de mener er essensiell for en kandidat med bachelorgrad i matteknologi. En spørreundersøkelse ble utviklet og sendt ut til 268 aktører fordelt på akademia, instituttsektor, industri og forvaltning. Den totale svarprosenten i undersøkelsen var $20,5 \%$, og $56 \%$ av respondentene var fra industrien. Uavhengig av respondentenes utdanning eller arbeidsplass var det stor enighet om de fem viktigste påstandene eller spørsmålene i undersøkelsen. Disse omhandlet overlevelse og vekst av mikroorganismer (Q21), mikroorganismenes påvirkning på produktkvalitet og mattrygghet og overvåkning av disse (Q36 og Q45), mikroorganismer og sykdom (Q43), samt bruk av prosessteknologi påvirker mikrobiota (Q44). Begrepstesen ble designet for å kunne vurdere studentenes forståelse av matmikrobiologi for, underveis og etter gjennomført bachelorstudium. Første gjennomkjøring av testen viser at flere iterasjoner er nødvendig før en pålitelig metode er etablert.
\end{abstract}

\section{INNLEDNING}

Bachelor utdanning i matteknologi ved NTNU er en praksisnær utdanning, hvor autentisk erfaring er et sentralt element for å sikre studiet arbeidslivsrelevans. Innenfor fagområdet matmikrobiologi og mattrygghet er filmatiserte case (Jakobsen et al., 2020) og epidemiologisk rollespill (Karlsen et al., 2015) utviklet i samarbeid med matbransjen for å trekke bransjens utfordringer inn i emneundervisningen. For å evaluere effekt av nye læringsaktiviteter er det viktig å etablere måleinstrumenter for å måle studentgruppers forståelse av faget. Begrepstester (concept inventories) finnes innenfor ulike fagfelt (Eggen et al., 2017; Paustian et al., 2017) og består av en serie flervalgspørsmål som skal avdekke studentgruppens dybdeforståelse og eventuelle misforståelser av sentrale faglige konsepter og begreper (Adams \& Wieman, 2011). Resultatene kan brukes til å sammenligne effekten av ulike undervisningsmetoder, og til å justere kurs underveis dersom misforståelser oppdages (Eggen et al., 2017). Dette gir verdifull informasjon som kan brukes for å utvikle undervisningens innhold. Begrepstester er utviklet innen ulike grener av mikrobiologien (Fisher et al., 2011; Paustian et al., 2017; Seitz et al., 2017), men ikke innen matmikrobiologi. Ofte involveres ekspertgrupper i utviklingen av slike tester, eksempelvis universitets kollegium (Paustian et al., 2017) eller større vitenskapelige nettverk (Horak et al., 2015). For å sikre arbeidslivets syn på hvilke temaer innen mikrobiologi som er sentralt for yrkesutførelsen, valgte vi å inkludere et bredt arbeidsliv i utviklingen av begrepstestesten i matmikrobiologi, dvs. matindustri, instituttsektor, universitet- og høyskolesektoren, samt forvaltning. Overordnet målsetting for utvikling av en begrepstest i matmikrobiologi var å vurdere studentenes forståelse av matmikrobiologi før, underveis og etter gjennomføring av bachelorstudiet i matteknologi.

\section{METODE}

Bachelorstudiet i matteknologi har flere obligatoriske mikrobiologirelaterte emner fordelt på alle årstrinn. Begrepstesten er derfor designet for å kunne vurdere studentenes forståelse av matmikrobiologi før (pre-test), underveis ( 3 og 5 semester) og etter (post-test) gjennomført bachelorstudium. Begrepstesten skal utvikles gjennom flere trinn (Tabell 1) basert på modifisert metodikk av Adams and Wieman (Adams \& Wieman, 2011). I artikkelen presenteres i hovedsak trinn 1-4. Utgangspunktet er eksisterende tester innenfor ulike grener av mikrobiologien (Merkel \& the ASM Task Force on Curriculum Guidelines for Undergraduate Microbiology, 2012; Paustian et al., 2017; Stevens et al., 2017), forfatternes egen undervisningserfaring og læringsutbytte innen matmikrobiologi på 
studieprogram- og emnenivå. Normalt kreves flere iterasjoner av steg 4-7 for å utvikle en fullverdig test (Adams \& Wieman, 2011).

Tabell 1 Trinnene i utvikling av begrepstest i matmikrobiologi.

\begin{tabular}{|l|l|l|}
\hline Trinn & Oppgave & Hvordan \\
\hline 1 & $\begin{array}{l}\text { Utvelgelse av begreper innen mat } \\
\text { mikrobiologi som er viktige for studie }\end{array}$ & $\begin{array}{l}\text { Tar utgangspunkt i eksisterende tester innen nærliggende } \\
\text { fagområder, samt egen undervisningserfaring, og studiets } \\
\text { læringsutbytte }\end{array}$ \\
\hline 2 & Avdekke matbransjens interessefelt & Spørreundersøkelse \\
\hline 3 & Formulere begrepstester & $\begin{array}{l}\text { Utvikling av spørsmål basert på eksisterende tester og } \\
\text { spørreundersøkelsen. Kollegadiskusjon om spørsmålene. }\end{array}$ \\
\hline 4 & $\begin{array}{l}\text { Identifisere hva studentene tenker om } \\
\text { de utvalgte begrepene }\end{array}$ & $\begin{array}{l}\text { Begrepstester } 1.0 \text { testet på et utvalg av studenter. Identifisere } \\
\text { misforståelser. }\end{array}$ \\
\hline 5 & Faglig validering & Begrepstester 1.0 testet på et ekspertpanel \\
\hline 6 & $\begin{array}{l}\text { Dypere forståelse av studenters og } \\
\text { eksperters oppfattelse av spørsmålene }\end{array}$ & $\begin{array}{l}\text { Fokusgruppeintervjuer av studenter og eksperter som har } \\
\text { gjennomført testen. Ekspertene skal ikke ha deltatt i utviklingen } \\
\text { av testen }\end{array}$ \\
\hline 7 & $\begin{array}{l}\text { Analyse av testens pålitelighet og } \\
\text { diskriminerende evne }\end{array}$ & Statistisk validering \\
\hline
\end{tabular}

\subsection{Spørreundersøkelse til matbransjen}

Det ble utviklet et elektronisk spørreskjema i programvaren EyeQuestion ${ }^{\circledR}$. Lenken til undersøkelsen ble distribuert via epost til 268 arbeidstakere i matbransjen innenfor industri, forvaltning, forskning og utdanning med arbeidsoppgaver relatert til matmikrobiologi. Spørreskjemaet inneholdt spørsmål relatert respondentens bakgrunn som stillingskategori, utdanningsnivå, sektor (forvaltning, industri, universitet og høyskole eller instituttsektor). Respondentene ble bedt om å gradere viktigheten av kunnskap om åtte ulike tema innen mikrobiologi og matmikrobiologi (Tabell 2) for deres arbeidssted og -oppgaver. Det ble benyttet avkrysning på en 5 punkts likert-skala fra 1 (lite viktig) til 5 (veldig viktig). Hvert tema hadde tre til fem påstander eller spørsmål.

Tabell 2 Tema dekket $i$ spørreundersøkelsen til matbransjen med eksempler på påstander eller spørsmål (Q) innenfor hvert tema

\begin{tabular}{|l|l|l|}
\hline Tema & $\begin{array}{l}\text { Spørsmåls- } \\
\text { nummer }\end{array}$ & Eksempler på påstander eller spørsmål innen temaet \\
\hline Bakgrunnsopplysninger & Q1-4 & Q2: Hva er din høyeste utdanning etter videregående skole? \\
\hline Evolusjon & Q6-10 & $\begin{array}{l}\text { Q7: Mutasjoner og horisontal genoverføring fra mange } \\
\text { forskjellige mikromiljø, har selektert for en stor variasjon av } \\
\text { mikroorganismer }\end{array}$ \\
\hline Celle struktur og funksjon & Q12-16 & $\begin{array}{l}\text { Q14: Bakterier og Arkebakterier har spesielle strukturer (eks. } \\
\text { endosporer) som ofte gir livsviktige egenskaper }\end{array}$ \\
\hline Metabolisme & Q18-21 & $\begin{array}{l}\text { Q21: Vekst av mikroorganismer kan kontrolleres på fysiske, kjemiske, } \\
\text { mekaniske eller biologiske måter }\end{array}$ \\
\hline $\begin{array}{l}\text { Informasjonsflyt og } \\
\text { genetikk }\end{array}$ & Q23-27 & Q27: Cellegenomer kan manipuleres til å endre cellefunksjon \\
\hline Mikrobielle systemer & Q29-32 & Q30: De fleste bakterier i naturen lever i biofilm \\
\hline Metode og dyrking & Q34-36 & $\begin{array}{l}\text { Q36: Produktkvalitet- og trygghet kan overvåkes ved mikrobiologiske } \\
\text { indikatorer }\end{array}$ \\
\hline $\begin{array}{l}\text { Mikroorganismenes } \\
\text { betydning }\end{array}$ & Q38-41 & $\begin{array}{l}\text { Q38: Mikroorganismer er viktig for livet som vi kjenner det (eks. } \\
\text { biokjemiske sykluser, mikrobiota i planter og dyr). }\end{array}$ \\
\hline Matmikrobiologi & Q43-45 & $\begin{array}{l}\text { Q46: Faktorer (eks. prosessfaktorer, mikroorganismens egenskaper, } \\
\text { råvareegenskaper) påvirker den mikrobielle økologien i næringsmidler } \\
\text { over tid. }\end{array}$ \\
\hline
\end{tabular}




\subsection{Utvikling av begrepstest i matmikrobiologi 1.0}

Spørsmålene i begrepstesten ble kategorisert innenfor de samme åtte temaene som angitt i tabell 2 . Totalt ble det utviklet 33 spørsmål. Pre-testen bestod av 15 av disse spørsmålene, og disse var av mer generell karakter enn de resterende 18 fagspesifikke spørsmålene. Hensikten med en forenklet pre-test er å øke forståelsen av studentenes kunnskap fra videregående skole. Hvert enkelt spørsmål bestod av fire deler som vist i Figur 1. Begrepstesten ble prøvd ut for 43 studenter i tredje årskull fordelt på to testrunde hvor den en ble gjennomført under overvåkning i klasserom uten tilgang på hjelpemidler (16 studenter) og den andre ble gjennomført digitalt uten overvåkning, men med oppfordring om å ikke benytte hjelpemidler (27 studenter). Studentene fikk spørsmålene i tilfeldig rekkefølge. Frekvensanalyse og deskriptiv statistikk av data fra spørreundersøkelsen og begrepstesten ble gjort ved hjelp av EyeQuestion ${ }^{\circledR}$ og Excel.

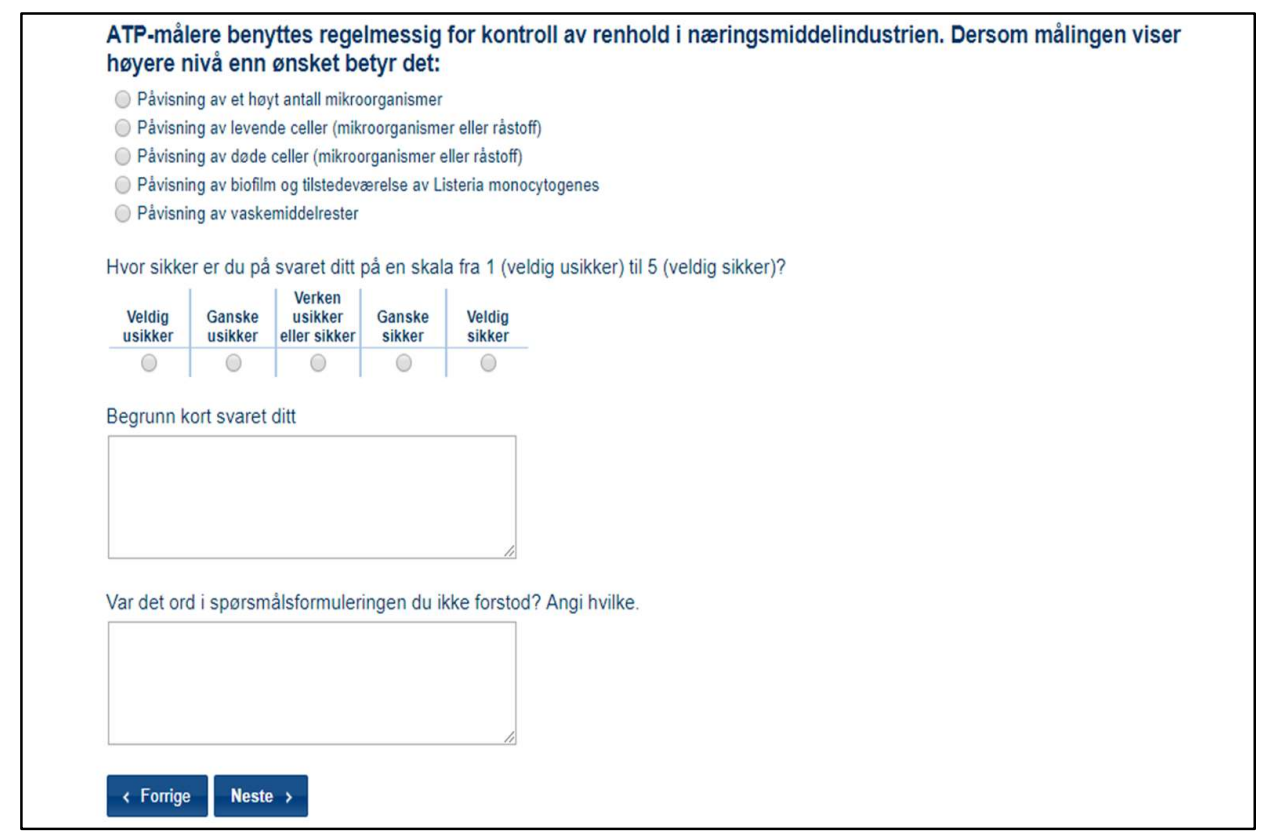

Fig. 1. Eksempel på spørsmål fra begrepstest for å teste forståelse av ATP-måling og anvendelse $i$ noeringsmiddelindustrien.

\section{RESULTATER OG DISKUSJON}

\subsection{Spørreundersøkelse om matbransjens syn på undervisning i matmikrobiologi}

Spørreundersøkelsen til matbransjen ble besvart av 55 av 268 respondenter $(20,5 \%)$ fra matbransjen, hvorav $56 \%$ av de som besvarte undersøkelsen jobbet i industribedrifter. Majoriteten av respondentene (92\%) hadde gjennomført høyere utdanning, fordelt på bachelor- $(38 \%)$, master- $(38 \%)$ eller doktor$(20 \%)$ nivå. Uavhengig av utdanning eller arbeidsplass var det stor enighet om de fem viktigste påstandene i undersøkelsen. Disse omhandlet overlevelse og vekst av mikroorganismer (Q21), mikroorganismenes påvirkning på produktkvalitet og mattrygghet og overvåkning av disse (Q36 og Q45), mikroorganismer og sykdom (Q43), samt bruk av prosessteknologi påvirker mikrobiota (Q44). Innspill fra arbeidslivet bidrar til å sikre relevans i emneundervisningen og er en ny tilnærming vi ikke har sett $\mathrm{i}$ tidligere publiserte begrepstester.

\subsection{Erfaring med utvikling av begrepstester}

De 16 studentene som besvarte begrepstesten under overvåkning brukte mellom 30 og 65 minutter (gjennomsnitt 47 minutter) på å besvare testen. Dette er innenfor området anbefalt for de fleste lignende tester innen eksempelvis fysikk (PhysPort, 2020). Standardisering av tid studentene får til å gjennomføre testen er viktig for å kunne sammenligne resultatene til ulike studentgrupper (Madsen et al., 2017). Overordnet ble det ikke funnet direkte sammenheng mellom andel riktige svar og om studentene gjennomførtes testen med eller uten overvåkning og resultatene er derfor slått sammen. Andelen korrekte svar for hvert spørsmål og andel studenter som oppgir at de er ganske eller helt sikre på sine 
svar er angitt i Figur 2. Studentene ble bedt om å angi hvor sikre de var på svaret, gjerne begrunnet svare og angi begreper de ikke forstod for å etablere mer innsikt i hvorfor de velger sitt svar. Flervalgstester kan besvares med gjetning, men i sammenheng med begrepstester er antagelig dette mest et problem for fagområder som er veldig ukjent for studentene. I slike tilfeller anbefales ofte kun bruk av post-tester etter et emne er gjennomført (Madsen et al., 2017). I vår studie ser vi at det ikke alltid er samsvar mellom andel riktige svar og hvor sikre studentene er på svaret. Eksempelvis svarer kun $12 \%$ rett på spørsmål 12 , men $55 \%$ av studentene er likevel ganske eller helst sikre på eget svar. For spørsmål 16 ser vi motsatt effekt, $93 \%$ svarer riktig, men kun $26 \%$ av studentene er ganske eller helst sikre på eget svar. En dypere forståelse av dette kan oppnås eksempelvis gjennom fokusgruppeintervju av studentene. Andelen riktige besvarelser varierer fra 12 til $98 \%$ for de utviklede spørsmålene, med en gjennomsnittlig verdi på 55,9\%. Optimal andel studenter som svarer riktige per spørsmål er avhengig av spørsmålstype, men ofte aksepteres 30-90\% (Eggen et al., 2017). De spørsmålene som er langt utenfor disse grensene bør omformuleres. Resultatene presentert i Figur 2 representerer to gjennomkjøringer med studenter som snart er ferdig med bachelorstudiet. Det er viktig å gjennomføre pre-testen også på studenter i førsteklasse før det gjøres endringer på spørsmål 1-15. En grundig analyse av studentenes begrunnelser for sine valg vil også bli gjort før en revidert versjon av testen er ferdigstilt.
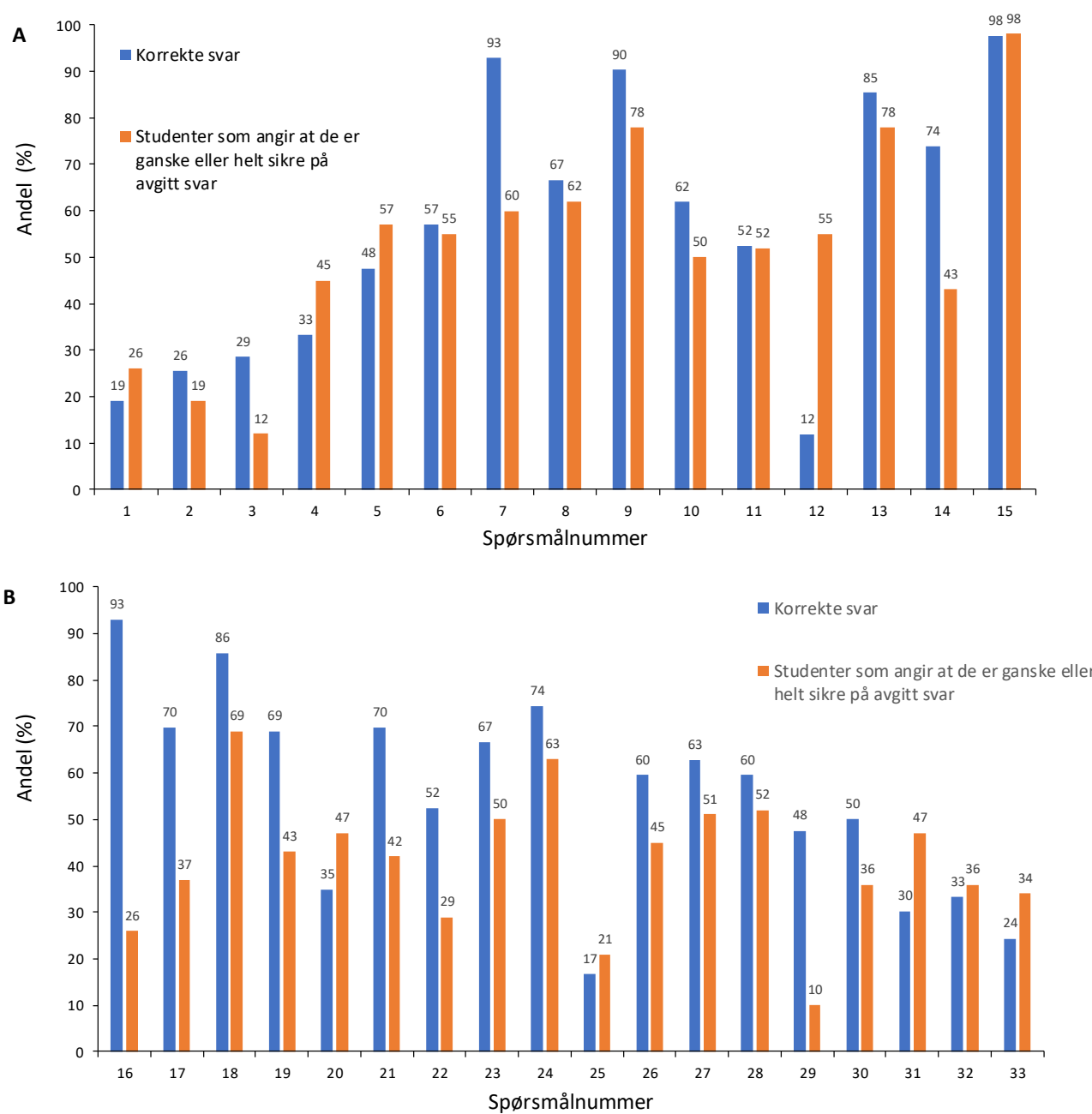

Fig. 2. Andelen korrekte svar og andel studenter som angir at de er ganske eller veldig sikre på sine svar ved første utprøving av pre-testen (A) og ekstra spørsmålene til underveis og post-tes $t(B)$ for studenter (n=43) i 5 6.semester. 


\section{VIDERE ARBEID}

Første utgave av en begrepstest i matmikrobiologi er utviklet. Testen skal videre optimaliseres gjennom utprøvning på førsteklasse studenter, utprøvning og tilbakemelding fra et ekspertpanel og statistiske analyser for å sikre å sikre en pålitelig og diskriminerende test.

\section{REFERENCES}

Adams, W. K., \& Wieman, C. E. (2011). Development and Validation of Instruments to Measure Learning of Expert-Like Thinking. International Journal of Science Education, 33(9), 1289-1312. https://doi.org/10.1080/09500693.2010.512369

Eggen, P. O., Persson, J., Jacobsen, E. E., \& Hafskjold, B. (2017). Development of an inventory for Alternative Conceptions among students in chemistry. . LUMAT: International Journal on Math, Science and Technology Education, 5(1), 1-11. https://doi.org/https://doi.org/10.31129/LUMAT.5.1.115

Fisher, K. M., Williams, K. S., \& Lineback, J. E. (2011). Osmosis and diffusion conceptual assessment. CBE Life Sci Educ, 10(4), 418-429. https://doi.org/10.1187/cbe.11-04-0038

Horak, R. E. A., Merkel, S., \& Chang, A. (2015). The ASM Curriculum Guidelines for Undergraduate Microbiology: A Case Study of the Advocacy Role of Societies in Reform Efforts. Journal of microbiology \& biology education, 16(1), 100-104. https://doi.org/10.1128/jmbe.v16i1.915

Jakobsen, A. N., Mehli, L., \& Hoel, S. (2020). Arbeidslivets perspektiv inn i klasserommet via filmatiserte case. Uniped, 43(4), 312-330. https://doi.org/10.18261/issn.1893-8981-2020-04-04

Karlsen, H., Mehli, L., Wahl, E., \& Staberg, R. L. (2015). Teaching outbreak investigation to undergraduate food technologists. British Food Journal, 117(2), 766-778. https://doi.org/https://doi.org/10.1108/BFJ-022014-0062

Madsen, A., McKagan, S. B., \& Sayre, E. C. (2017). Best Practices for Administering Concept Inventories. The Physics Teacher, 55(9), 530-536. https://doi.org/10.1119/1.5011826

Merkel, S., \& the ASM Task Force on Curriculum Guidelines for Undergraduate Microbiology. (2012). The Development of Curricular Guidelines for Introductory Microbiology that Focus on Understanding. Journal of Microbiology \&amp; Biology Education, 13(1), 32-38. https://doi.org/http://doi.org/10.1128/jmbe.v13i1.363

Paustian, T. D., Briggs, A. G., Brennan, R. E., Boury, N., Buchner, J., Harris, S., Horak, R. E. A., Hughes, L. E., Katz-Amburn, D. S., Massimelli, M. J., McDonald, A. H., Primm, T. P., Smith, A. C., Stevens, A. M., \& Yung, S. B. (2017). Development, Validation, and Application of the Microbiology Concept Inventory. Journal of microbiology \& biology education, 18(3), 18.13.49. https://doi.org/10.1128/jmbe.v18i3.1320

PhysPort. (2020). Supporting physics teaching with research-based resources. http://www.physport.org/assessments.

Seitz, H. M., Horak, R. E. A., Howard, M. W., Kluckhohn Jones, L. W., Muth, T., Parker, C., Rediske, A. P., \& Whitehurst, M. M. (2017). Development and Validation of the Microbiology for Health Sciences Concept Inventory $\dagger$. Journal of Microbiology \&amp; Biology Education, 18(3), -. https://doi.org/doi:10.1128/jmbe.v18i3.1322

Stevens, A. M., Smith, A. C., Marbach-Ad, G., Balcom, S. A., Buchner, J., Daniel, S. L., DeStefano, J. J., ElSayed, N. M., Frauwirth, K., Lee, V. T., McIver, K. S., Melville, S. B., Mosser, D. M., Popham, D. L., Scharf, B. E., Schubot, F. D., Seyler, R. W., Shields, P. A., Song, W., Stein, D. C., Stewart, R. C., Thompson, K. V., Yang, Z., \& Yarwood, S. A. (2017). Using a Concept Inventory to Reveal Student Thinking Associated with Common Misconceptions about Antibiotic Resistance. Journal of Microbiology \&amp; Biology Education, 18(1). https://doi.org/doi:10.1128/jmbe.v18i1.1281 